$$
\text { 趈 }
$$

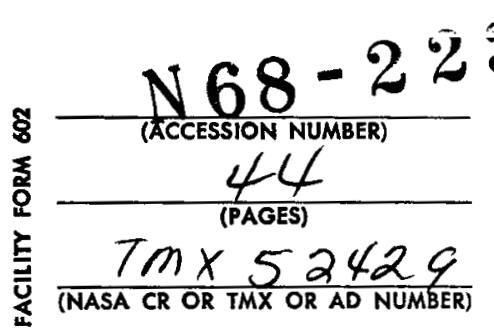

\section{GPO PRICE \$}

CFSTI PRICE(S) \$

Hard copy $(\mathrm{HC}) \_3,00$

Microfiche (MF)

65

\title{
AN EXPERIMENTAL INVESTIGATION OF A HIGH-VOLTAGE ELECTRON-BOMBARDMENT ION THRUSTER
}

by David C. Byers

Lewis Research Center

Cleveland, Ohio

TECHNICAL PAPER proposed for

- presentation at Spring National Meeting of the Electrochemical Society

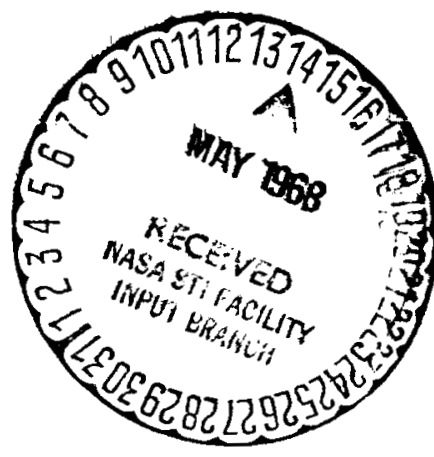

Boston, Massachusetts, May 5-9, 1968

NATIONAL AERONAUTICS AND SPACE ADMINISTRATION - WASHINGTON, D.C. 1968 


\section{AN EXPERIMENTAL INVESTIGATION OF A HIGH-VOLTAGE ELECTRON-BOMBARDMENT ION THRUSTER \\ by David C. Byers \\ Lewis Research Center \\ Cleveland, Ohio}

TECHNICAL PAPER proposed for presentation at

Spring National Meeting

of the Electrochemical Society

Boston, Massachusetts, May 5-9, 1968

NATIONAL AERONAUTICS AND SPACE ADMINISTRATION 


\title{
AN EXPERIMENTAL INVESTIGATION OF A HIGH-VOLTAGE \\ ELEC TRON-BOMBARDMENT ION THRUSTER
}

\author{
by David C. Byers \\ Lewis Research Center \\ National Aeronautics and Space Administration \\ Cleveland, Ohio
}

\section{SUMMARY}

The performance of a mercury electron-bombardment thruster at large values of net accelerating potential is described. A 20-centimeter-diameter thruster was tested at values of ion beam current and net accelerating potential up to 0.165 ampere and 70 kilovolts, respectively. A maximum beam power of about 10 kilowatts was obtained. The maximum supportable electric field strength between accelerator grids was approximately constant at $2 \times 10^{6}$ volts per meter for spacings between 0.5 and 3.0 centimeters. The ion chamber performance was qualitatively similar to that at low accelerating voltage. The energy dissipated per beam ion in the ion-chamber discharge was related to the percentage of Child's law ion current extracted over a wide range of accelerator spacings and potentials. The maximum percentages of Child's law current transmitted were about 60 and 80 percent for thrusters with 20 and 7.5 centimeter-diameter accelerator grids, respectively, and were essentially independent of grid spacing and thickness. Ion focusing characteristics, at ion beam current densities of about 10 amperes per square meter, indicated that the ratio of center-to-center grid spacing to 
grid thickness should be between about 2.5 and 4 to avoid direct ion impingement.

Accelerator grid lifetimes up to two years were calculated for net accelerating potentials between 20 and 70 kilovolts, based on measured values of ion sputtering rates and ion impingement currents. The lifetimes were a function of the percentage of Child's law current at which the plates were operated.

The power efficiency was measured and found to be consistent with data taken with low voltage thrusters operated at similar conditions. A power efficiency of 0.8 was obtained at a net accelerating potential of 18 kilovolts and rose to 0.88 at a net accelerating potential of 36 kilovolts. Overall thruster efficiencies of about 0.80 and 0.82 were obtained at net accelerating potentials of 28 and 36 kilovolts, respectively.

\section{INTRODUCTION}

The operation of electron-bombardment thrusters at high values of net acceleration potential has promise of increasing the overall thruster efficiency (ref. 1). Higher specific impulses (and therefore higher accelerating voltage) also become more necessary as mission difficulty increases and propulsion system specific mass decreases (ref. 2). In addition, degradation of the maximum supportable field strength at high voltages, often found in high voltage breakdown studies (ref. 3), would reduce the maximum thrust per unit area of the thrusters (ref. 4). 
This investigation was carried out to determine the operating characteristics of mercury electron-bombardment thrusters at net accelerating potentials between 10,000 and 70,000 volts. Previous thruster data had been limited to a maximum potential of approximately 10,000 volts (ref. 5).

The discharge chamber efficiency and the current carrying characteristics of the high voltage grid system were investigated and compared with data obtained at low values of net accelerating potential (ref. 6). Ion impingement currents were measured and compared with an existing analysis (ref. 7) extrapolated to high voltage. Overall thruster efficiencies are discussed both as a function of propellant utilization efficiency and net accelerating potential and in addition are compared with low voltage data.

\section{SYMBOL LIST}

$\mathrm{A}_{\mathrm{A}}$ open area of accelerator on screen grid, $\mathrm{m}^{2}$

A flow area of ions, $\mathrm{m}^{2}$

$\mathrm{A}_{\mathrm{O}} \quad$ nominal thruster area, $\mathrm{m}^{2}$

B magnetic field strength, $\mathrm{W} / \mathrm{m}^{2}$

D accelerator plate hole diameter, $\mathrm{m}$

$\mathrm{f}(\mathrm{R}) \quad 1 / \mathrm{R}^{3 / 2}+3 / \mathrm{R}-4$

$I_{\text {sp }} \quad$ specific impulse, sec

J current, A

$\mathrm{J}_{\mathrm{O}} \quad$ current equivalent neutral flow rate, A 
j current density, $\mathrm{A} / \mathrm{m}^{2}$

$\ell \quad$ grid-to-grid spacing, $\mathrm{cm}$

$l_{4} \quad$ center-to-center grid spacing, cm

m mass, $\mathrm{kg}$

q charge of an electron, $\mathrm{C}$

$\mathrm{R}$ ratio of net-to-total accelerating potential, $\mathrm{v}_{\mathrm{I}} / \mathrm{v}_{\mathrm{I}}^{+}\left|\mathrm{v}_{\mathrm{A}}\right|$

t accelerator grid thickness, $\mathrm{cm}$

$\mathrm{V}$ potential, $\mathrm{V}$

$\Delta \mathrm{V}$ potential difference, $\mathrm{V}$

$\beta \quad 4 \epsilon_{\mathrm{o}} / 9 \sqrt{2 \mathrm{q} / \mathrm{m}}=3.86 \times 10^{-9} \mathrm{mks}$ units for $\mathrm{H}_{\mathrm{g}}^{+1}$ ions

$\epsilon_{\mathrm{o}} \quad$ permittivity of free space, $8.85 \times 10^{-12} \mathrm{C}^{2} /(\mathrm{N})\left(\mathrm{m}^{2}\right)$

$\eta \quad$ efficiency

$\tau \quad$ lifetime, $\mathrm{hr}$

Subscripts:

A accelerator

B beam

$\mathrm{CH}$ Child's law

I ion chamber

n neutral

p power

T total

U utilization 


\section{APPARATUS AND PROCEDURE}

\section{Thruster}

The electron-bombardment thruster utilized in this program is shown in figure 1. The principle of operation of the thruster has been described in many references (e.g., ref. 5). In brief, a mercury vaporizer was heated with steam slightly above atmospheric pressure to provide close thermal control of the vaporizer. Interchangeable vaporizer orifices were utilized to change propellant flow rates. The propellant flowed into the ionization chamber through an annular slot distributor. A small screen was between the vaporizer and the distributor to prevent plasma leakage to the vaporizer (ref. 8).

Electrons are emitted from the cathode and reach an energy nearly equal to the potential difference between the anode and the cathode. These electrons, which are constrained by an axial magnetic field, ionize some of the mercury. The mercury ions diffuse to the accelerator grid region and are accelerated into the exhaust beam.

For all tests, a 20-centimeter-diameter anode was used. The cathode was tantalum ribbon 0.05 millimeter thick, 40 millimeters long, and about 5 millimeters wide.

Accelerator grid system. - A typical accelerator configuration is shown in sketch (a). 


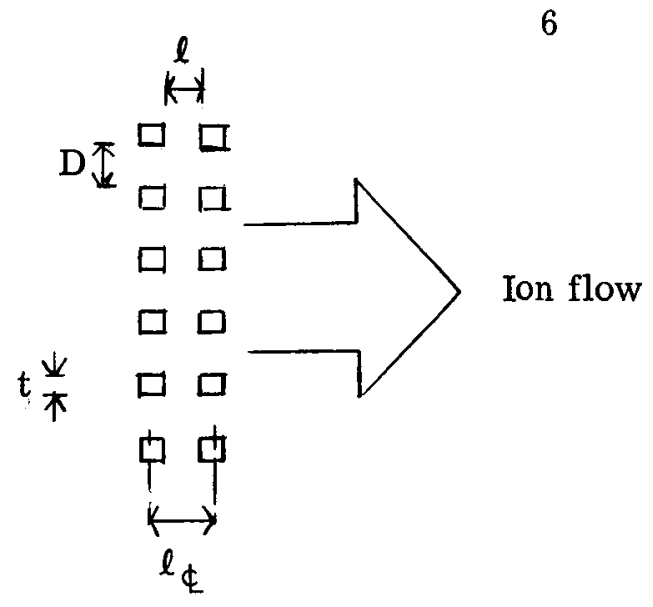

(a)

The value of the ratio of center-to-center grid spacing to hole diameter, $\ell_{\Phi} / D$, was varied between 0.5 to 3.0 by insertion of shims between the downstream insulators and the screen grid extensions (fig. 1). The screen and accelerator grids were of equal thickness unless otherwise stated. All the data presented in the figures of this report were taken with accelerator grids with hole diameters of 2.2 centimeters because, as will be later explained, the use of larger holes, 5 centimeters, led to undesirable thruster performance.

Insulators. - The high voltage thruster was initially designed with spherical insulators scaled from insulators used successfully up to about 10 kilovolts. The 5-centimeter-diameter aluminum oxide spheres were capable of supporting 22 kilovolts before severe flashover occurred. Insulators utilizing shielded negative terminals were also fabricated and tested. These tests are presented in the RESULTS AND DISCUSSION. The final design, shown in figure 2, was capable of withstanding potentials up to 250 kilovolts in vacuum. 
Facility

The facility was one of the 5-foot-diameter, 16-foot-long vacuum tanks at the NASA Lewis Research Center. The tank has three 32 -inch oil diffusion pumps feeding into a common ejector pump followed by a mechanical pump. Cryogenic pumping $\left(\mathrm{LN}_{2}\right)$ was used in conjunction with the diffusion pumps so that thruster operation was possible in the $10^{-6}$ torr pressure range. A more complete description of this facility is included in reference 9 .

\section{Measurements}

All electrical measurements in this program were made with standard meters with an accuracy of about 3 percent at full scale deflection. The propellant utilization efficiency could not be fixed to much better than 5 percent. This accuracy was estimated from measured variation in neutral propellant flow rate from several tests where the same orifice size was utilized.

\section{RESULTS AND DISCUSSION}

The results of the high voltage breakdown characteristics over insulators and between accelerator grids are described first. The ion chamber performance is considered next. The effects of accelerator parameters on the maximum attainable ion current are then presented followed by a discussion of the accelerator lifetimes to be expected at high voltage. Finally a discussion of overall thruster efficiencies at high voltage is presented. 


\section{High Voltage Breakdown Studies}

The maximum value of the thrust per unit area of a Child's law current limited system is directly proportional to the square of the electric field supported by the accelerator grid system (ref. 4). The value of the maximum supportable field strength in vacuum has, in general, been found to decrease with increasing spacing (ref. 3). The voltage breakdown characteristics of accelerator grids at spacings of interest in this program (roughly 0.5 to $5 \mathrm{~cm}$ ) were therefore studied.

In addition, initial tests indicated that spherical insulators were unacceptable for use at the intended voltage levels. A test program was carried out to find a suitable insulator design.

Insulator studies. - Spherical insulators (such as utilized in low voltage thrusters), 5 centimeters in diameter, were found to breakdown at 22 kilovolts. A program was carried out to improve the insulator design to meet the voltage requirements of the study. The guideline for this program was the data of references 12 and 13 which indicated that the primary cause of insulator flashover was electron emission initiating at the negative metaldielectric junction.

The program consisted of three phases. Initial tests utilized small bakelite samples (for convenience in fabrication) in a small bell jar facility with total potentials up to 50 kilovolts available. Intermediate studies 
were conducted on full size insulators, fabricated from various ceramic materials, in the thruster vacuum facility. Tests on the final design (fig. 2), fabricated from aluminum oxide, were performed in a high voltage bell jar facility with total applied potentials up to 400 kilovolts. The final insulator was found to eliminate insulator flashover breakdown up to voltages of 250 kilovolts, at which point the insulator failed due to puncture through the dielectric. The design increased the flashover voltage for two reasons. First, the electric fields which can liberate electrons are reduced near the negative junction, as suggested by reference 12 . Secondly, the discharge at the negative junction was constrained to the hollowed out section of the insulator. As in most high voltage tests, occasional breakdowns occur during initial testing. For example, in one test two flashover breakdowns occurred as the voltage was being raised to 250 kilovolts. The insulator then held for three hours at this potential without breakdown. This voltage level was sufficient because the total accelerating potential available for thruster operation was about 125 kilovolts.

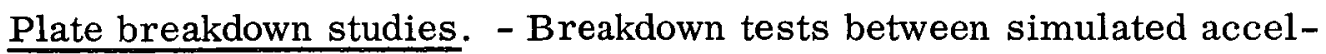
erator grids were carried out in a bell jar facility. The effects of spacing and surface conditioning on the maximum supportable electric field strength were investigated at voltages up to 285,000 volts. The grids were attached to independent holders which were connected to high voltage feed throughs at opposite ends of the bell jar. This mounting technique eliminated the need 
of spacing insulators and allowed comparison of grid-to-grid breakdown separate from insulator flashover.

Stainless steel plates 0.31 centimeter thick and 25 centimeters in diameter were fabricated. Plain plates and plate sets with up to 37 holes (all holes 2.54-cm diam) were utilized. The edges of one side of each of the plates were left unfinished while the edges of the opposite side were machined to approximately 0.06 centimeter radius.

The results of these tests are presented in figure 3 , where the maximum supportable field strength is plotted against the face-to-face spacing between the plates. Above the maximum field strength the breakdowns would become nearly continuous. In addition, this field strength was the highest that could be supported without breakdowns for times greater than about five minutes after prolonged conditioning (i.e., repeated breakdowns). A breakdown was defined as a discharge between the plates greater than 1 milliampere (which tripped the power supplies).

Figure 3 shows that the maximum supportable electric field does decrease with increasing spacing as expected. The fields are, however, considerably greater than the maximum supportable fields for low voltage thruster operation, which are generally from 2 to $3 \times 10^{6}$ volts per meter (ref. 7 ). Figure 3 also shows that the maximum field is somewhat dependent on the number of holes. In general, the voltage breakdown level decreased with the number of holes drilled in the plates. Although not shown, the critical electric 
field was larger when rounded edges rather than square edges faced each other. This difference in critical electric field was, however, always less than 20 percent. It is seen that the data agrees relatively well with the data of reference 10, which was taken with unpolished stainless steel plates.

It was found that the characteristics of the breakdowns which occurred at spacings less than 1 centimeter spacing differed substantially from those breakdowns at spacings greater than 1 centimeter. At the smaller spacings the breakdowns were localized, data were quite repeatable, and the current between the plates approached zero at the maximum voltage difference after conditioning for a few minutes. At larger spacings, however, breakdowns were not localized, the leakage current did not decrease significantly with time near the maximum field strength, and the data were never repeatable to much closer than about 20 percent. This was true whether the data was repeated in sequence, with up to 24 hours between tests, or following an intermediate spacing change. The lack of repeatability at spacings greater than 1 centimeter precluded both the identification of sources of prebreakdown leakage currents and prediction of the maximum supportable field strengths to better than 20 percent.

Thruster breakdown tests. - Data were taken throughout the thruster program of the maximum supportable field during thruster operation (utilizing the improved insulator design previously described). The results are 
shown in figure 4. Comparing these data with figure 3 it is seen that the levels of field strength are approximately a factor of 3 or 4 lower than those obtained in the bell jar tests. The data do not, however, show significant degradation from field strengths obtained previously with thrusters operating at lower voltages. The reason for the low maximum supportable field strength between grids of operating thrusters, as compared with breakdown between plates of the same physical geometry in vacuum is not certain.

During operation, however, the grids of a thruster suffer ion impingement, and become heated to about $700^{\circ} \mathrm{K}$ (ref. 7). These factors would probably tend to reduce the maximum supportable field strength.

\section{Ion Chamber Performance}

The ion chamber was tested over a large range of thruster operating conditions. In general, the qualitative trends were the same as those obtained with low voltage thrusters utilizing tantalum cathodes. This discharge energy required to form a beam ion, eV/ion, is defined as:

$$
\mathrm{eV} / \text { ion }=\frac{\Delta \mathrm{V}_{\mathrm{I}}\left(\mathrm{J}_{\mathrm{I}}-\mathrm{J}_{\mathrm{B}}\right)}{\mathrm{J}_{\mathrm{B}}}
$$

Figure 5 shows the eV/ion as a function of the propellant utilization efficiency, net accelerating potential, ion-chamber discharge potential, and magnetic field strength. As is generally true (ref. 5) the eV/ion increased with propellant utilization efficiency, decreased with net accelerating potential, and exhibited a minimum at some value of both ion chamber potential 
difference and magnetic field strength. These data are not optimum for a 20-centimeter thruster. Use of a discharge chamber configuration employing a hollow cathode (ref. 14) or different propellant introduction modes (ref. 15) would probably lower the chamber losses.

Discharge stability. - During the investigation it was found that some limits had to be placed upon various thruster parameters in order to maintain stable thruster operation. The instability of the discharge would manifest itself both by breakdowns from the thruster anode potential to ground and quenching of the ion-chamber discharge. Such instabilities are similar to those experienced during operation with short anodes (refs. 5 and 16). The factors most strongly affecting the discharge stability were the propellant utilization efficiency and the accelerator grid hole size. The grid spacing and thickness did not significantly affect stability over the range of values tested.

The discharge chamber was unstable with the 2.2 and 5.0-centimeter diameter grid holes at propellant utilization efficiencies greater than about 0.90 and 0.30 , respectively. Data presented herein at propellant utilization efficiencies greater than these values (with the specified hole sizes) were taken during repeated breakdowns and/or discharge quenching.

Operation with the large hole grids was characterized by very severe breakdowns which would often destroy the cathode. When wire mesh was placed over the screen grid holes (sketch b), breakdowns from the anode 


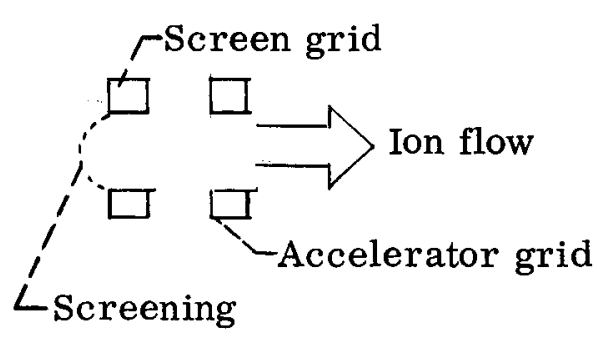

(b)

to ground were eliminated. Use of such screens proved unsatisfactory, however, because the mesh would quickly burn through. In addition, the $\mathrm{eV} /$ ion was 2 to 3 times that obtained without mesh screening.

The above statements indicate that the accelerator field can interact with the ion chamber plasma. The grid hole size strongly affected the maximum propellant utilization efficiency that could be attained. The data suggests that discharge quenching, at high utilization efficiencies, may be inherent with the grid geometries required at high voltage.

Accelerator spacing and net accelerating voltage. - Throughout the test it was found that the $\mathrm{eV} / \mathrm{ion}$ was strongly dependent upon the accelerator geometrical and electrical parameters within the region of stable discharge operation. Accelerator grids with hole diameters of 2.2 centimeters and 7 or 37 holes were utilized for the tests discussed below. The ratios of center-to-center spacing and grid thickness to the hole diameter were varied between 0.8 to 2.5 and 0.34 to 0.86 , respectively.

Figure 6 shows the energy loss per beam ion as a function of the center-to-center grid spacing. The center-to-center spacing was chosen 
because it allows reasonable agreement with Child's law currents (ref.6) and predicted values of charge-exchange ion impingement currents (ref. 7). It is seen from figure 6 that the $\mathrm{eV} /$ ion tends to increase with both grid spacing and thickness at fixed values of accelerating voltage and propellant utilization efficiency (the hole size was constant for the data of fig. 6).

To concisely present data over a wide variety of operating conditions, the $\mathrm{eV} /$ ion was plotted as a function of the ratio of beam current to the Child's law current predicted by use of the center-to-center grid spacing (ref. 6). This ratio is hereafter referred to as percentage of Child's law, and for reference is given by equation (2):

$$
\left(\frac{{ }^{J} \mathrm{~B}}{\mathrm{~J}_{\mathrm{CH}}}\right)=2.59 \times 10^{10} \frac{\mathrm{J}_{\mathrm{B}}{ }^{2} \dot{\mathrm{c}}}{\mathrm{A}_{\mathrm{A}} \Delta \mathrm{V}_{\mathrm{T}}^{3 / 2}}
$$

Figure 7 shows this variation and is typical of all data taken in that the enerby lost per beam ion always rose monotonically with the percentage of Child's law.

Comparison of figures $5(a)$ and 7 show that the eV/ion is less sensitive to the propellant utilization efficiency when the percentage of Child's law current, rather than the net accelerating potential, is held constant. This fact is more clearly demonstrated by figure 8 which presents, at one grid spacing, the variation of $\mathrm{eV} / \mathrm{ion}$ with propellant utilization efficiency at three values of percentage of Child's law ion current. 
For the data of figure 8, at a fixed percentage of Child's law, an increase of propellant utilization efficiency from 0.3 to 0.9 corresponded to increases of ion beam current and net accelerating potential by factors of about 3 and 2, respectively. At a fixed propellant utilization efficiency, the net accelerating potential decreased (eq. (1)) by a factor of about 1.4 as the percentage of Child's law current increased from 30 to 50 percent.

Figure 9 shows that to a good approximation the eV/ion was not a strong function of grid spacing if the accelerating voltage was adjusted to provide a constant percentage of Child's law ion current. The data of figure 6 (fixed net accelerating potential, 7 hole grid) indicate that the $\mathrm{eV} / \mathrm{ion}$ nearly doubled as the spacing ratio increased from 0.8 to 2.0. The increase in $\mathrm{eV} /$ ion for the same spacing ratio variation at fixed percentage of Child's law current (fig. 9) was about 15 percent.

The basic energy requirement of producing a beam ion is, of course, most strongly a function of propellant type and the geometrical and electrical parameters of the ionization chamber (ref. 17). Within this framework, however, the accelerator parameters can play an important role in determining the $\mathrm{eV} / \mathrm{ion}$.

The ion extraction efficiency could be a function of either the ion sheath withdrawal area or long range extraction phenomena such as axial electric field gradients in the discharge chamber. Figures 7 and 8 of reference 18 indicate that small changes in the percentage of Child's law can 
result in large variation in ion sheath withdrawal area. Reference 18 indicates, for example, that the sheath area increased by about 50 percent when the ion current was varied to decrease the percent Child's law from approximately 27 to 17 percent. On the other hand, increased extraction efficiency is almost certain to change the plasma parameters, at least near the accelerator grids. Variation of the electron temperature, for example, could affect the ion drift velocity toward the accelerator grids (ref. 17).

A consequence of the above discussion is that the $\mathrm{eV} / \mathrm{ion}$ does not decrease indefinitely with increasing net accelerating potential. For a fixed grid spacing the energy expended per beam ion will decrease with increasing acceleration voltage up to the voltage limit determined by grid-to-grid breakdown. In order to further increase the acceleration potential it is necessary to increase the grid spacing. An increase in spacing has the effect (eq. (2)) of increasing the percentage of Child's law current represented by a given ion beam current density and net accelerating potential, and as previously seen, the $\mathrm{eV} /$ ion will increase. This implies a serious limitation in the attainable discharge power losses or beam current densities with simple two grid accelerators at large spacings.

\section{Beam Current Density Measurements}

The value of the maximum attainable beam current density was of interest because of its direct influence upon the thrust per unit area. Calculation of the grid aperture effect (ref. 6) indicated that no decrease in the maximum 
transmitted percentage of Child's law ion current would occur due to operation at high voltage (large spacings).

Grid spacing and thickness. - Figure 10 shows the variation of the maximum percentage of Child's law current as a function of the ratio of accelerator grid spacing to hole diameter. Data for both the 37 and 7 hole grids (sketch c) are included in figure 10. The maximum beam current was determined by the "knee" method of reference 6 , and can contain considerable error due to the difficulty of locating the knee exactly. Briefly, the "knee" method is the determination of the total voltage between the grids at which the impingement current begins to rise rapidly when the thruster is operated at a constant beam current. For a fixed spacing the Child's law ion current can be calculated for the "knee" voltage and the data of figure 10 is the ratio of the actual ion current at the "knee" to the calculated Child's law value.

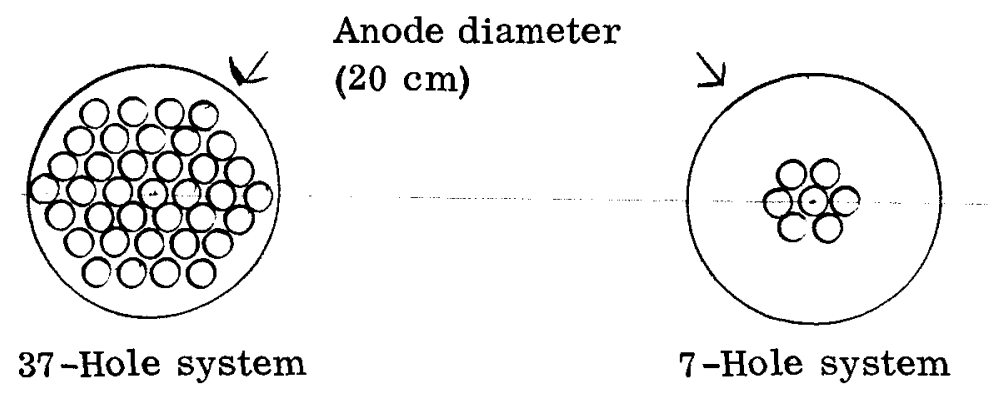

(c) 
It is seen from figure 10 that the value of the maximum percentage of Child's law current does not significantly vary with grid spacing for a fixed number of holes. The general levels of maximum percentage of Child's law ion currents were higher for the 7 hole than the 37 hole system. The defining diameters, within which all holes were contained, were about 7.5 and 20 centimeters, respectively, for the 7 and 37 hole configurations. It was found that closing the central 7 holes on the 37 hole system increased the maximum transmitted percentage of Child's law ion current for the remaining 30 holes but the maximum current from the thruster was reduced.

It is likely that there was a larger variation in the discharge ion density across the 37 hole system than the 7 hole system. The radial ion number density gradient is probably most strongly affected by the basic geometry of the discharge chamber which had a constant anode diameter for both grid configurations. The presence of a large ion density gradient thus might lead to defocusing of the central holes before the outer holes become defocused as the total thruster current approaches the Child's law current limit.

Focusing characteristics. - Tests were performed with 7-hole accelerator grids in order to evaluate the focusing characteristics over a large range of spacings and grid thicknesses. Figure 11 shows the variation of the ratio of impingement to beam current as a function of the percentage of Child's law ion current for several grid configurations. The propellant utilization efficiency was low for the tests with the 7 -hole grid system (0.17). As will be 
discussed later, the general levels of the ratio of ion impingement to beam current will increase with decreasing propellant utilization efficiency. Focusing effects should not, however, be strongly affected by the utilization efficiency. The neutral propellant flow rate and beam current were constant for the data of figure 11 and variation in percentage of Child's law ion current reflects variation of the total accelerating potential. It is seen from figure 11 that as the percentage of Child's law increased, or the net accelerating potential decreased, the ion impingement first decreased slowly, became relatively constant, and then increased sharply at some value which is a function of grid spacing and thickness.

The effect of various geometric accelerator grid parameters on ion focusing is seen more clearly on figure 12 which shows the ratio of ion impingement to ion beam current as a function of grid spacing at three values of percentage of Child's law ion current. The data were taken at fixed values of ion beam current, ratio of net to total accelerating potential, and propellant utilization efficiency.

It is seen from figure 12 that the variation of the impingement current with spacing is a function of both the percentage of Child's law ion current and the ratio of grid thickness to hole diameter. In general, at 30 percent of Child's law the impingement current decreased slightly with increasing grid thickness and was rather insensitive to the grid spacing. At 80 percent of Child's law ion current the impingement current is, however, a rather 
sensitive function of the grid geometry. The ion beam appeared to defocus at both large and small spacing for the thinner grids (data were not taken with the thickest grids at a large enough spacing for defocusing to occur). As the grid thickness increased, both the maximum and minimum spacing at which defocusing initiated increased. A crossplot of the data of figure 11 indicates that defocusing occurred when the ratio of grid spacing to thickness became less than about 2.5 and greater than about 4.0 . The value of the grid spacing to thickness ratio at which the minimum impingement occurred was about 3.1 for the two thinnest grid configurations (crossplot of figs. 12(b) and (c)).

The data of figure 12 indicate that if thruster operation at a large value of percentage of Child's law is desired, care is necessary in selection of the grid geometry in order to operate at low values of impingement current. If the thruster is to be operated at a low percentage of Child's law, the impingement will be substantially constant over a wide range of grid geometries. The lack of dependence of the impingement current upon the grid configuration at low values of percent Child's law is probably due to the fact that in this region the ion beam becomes strongly focused into the center of the accelerator holes (see figs. 9 and 10 of ref. 18). As the value of the percentage of Child's law increased, the ion beam spreads, due to sheath readjustment, and the ion focusing becomes more strongly dependent upon the specific grid geometry. 
Charge-exchange ion impingement. - In the region of good ion focusing the value of impingement current due to charge-exchange has been calculated in reference 7 . The value of the charge-exchange currents in the present investigation will differ from those of reference 7 due to the large differences in net accelerating potential and spacings utilized. For fixed values of neutral mass flow rate, propellant utilization efficiency and open area, the values of the charge-exchange current will be considerably larger than at low voltage operation. The cross section for charge exchange does decrease somewhat with increasing voltage. Large uncertainties exist in the literature, however, regarding the exact variation. For example, figure 13 is a plot of this variation comparing values from three different sources (refs. 19 to 21). For purposes of later calculation the charge-exchange cross section will be assumed to be constant at $5 \times 10^{-15} \mathrm{~cm}^{2}$ for the net accelerating potentials $(15,000$ to $70,000 \mathrm{~V})$ used in this investigation.

Figure 14 shows the variation of the ratio of impingement to beam current as a function of grid spacing. These data were taken with the 37 -hole grid system with a grid thickness to hole diameter ratio of 0.54 . This grid thickness ratio was selected as it allowed operation over a wide range of percentage of Child's law ion currents and accelerator grid spacings (fig. 12). Also shown are the calculated values of the impingement to beam current ratio obtained by use of equation (B16) of reference 7 . This equation is given below with the charge-exchange cross section assumed to be $5 \times 10^{-15} \mathrm{~cm}^{2}$ 
rather than $6 \times 10^{-15} \mathrm{~cm}^{2}$ as in reference 7 .

$$
\frac{J_{A}}{J_{B}}=2.63\left(1-\eta_{U}\right) J_{O}\left[1.5 \frac{\ell_{\Phi}}{A_{A}}+\sqrt{\frac{\beta V_{I}^{3 / 2} A_{I} f(R)}{A_{O}^{2} \eta_{U} J_{O}}}\right]
$$

It is seen from figure 14 that, in general, the values of ion impingement were within about a factor of 2 of those predicted from the calculated chargeexchange impingement current of reference 7 . This agreement, approximately the same as that obtained at low voltage (ref. 7), held as long as care was taken to operate in the aforementioned region of good focusing. It is thus likely that the impingement in the good focusing region was due primarly to charge-exchange ions. The data of figures 11 and 12 (7-hole grid) also agreed with equation (3). The higher values of impingement arose primarily because the low utilization efficiencies and reduced open area at which the 7 -hole grids were operated.

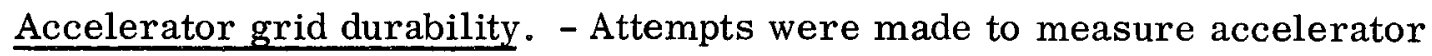
grid erosion rates on short term tests and the results are presented in figure 15. The value of the mass sputtering rate was 11 to $190 \mathrm{~g} /(\mathrm{amp})(\mathrm{hr})$ for tests ranging from 4 to 10 hours duration. Tests $1(28 \mathrm{kV})$ and $2(40 \mathrm{kV})$ were taken at 67 and 48 percent of Child's law current, respectively, while tests 3 $(40 \mathrm{kV})$ and $4(70 \mathrm{kV})$ were performed at 30 and 25 percent of Child's law current. It is likely that the tests at the higher percentages of Child's law current contained a larger proportion of direct ion impingement than those at the lower percentages of Child's law (figs. 11 and 12). The wide range in meas- 
ured mass sputtering rates could, however, arise from a number of other reasons, such as:

(1) Variation of the mass sputtering rate with the ion incidence angle. Reference 22 indicates, for example, that the mass sputtering rate of mercury ions varies by a factor of 15 as the ion incidence angle varies from $0^{\circ}$ $90^{\circ}$.

(2) The existence of secondary electron emission.

(3) Arc damage.

(4) Inaccuracies in measurement. The ratio of the mass loss to the mass of the accelerator plate was nominally between about $10^{-4}$ and $10^{-5}$ for the data of figure 15. For mass sputtering rates less than $200 \mathrm{~g} /(\mathrm{amp})(\mathrm{hr})$, tests in excess of about 100 hours would have been required to produce mass losses greater than about 1 percent of the accelerator grid mass.

Although an accurate calculation of accelerator grid lifetime cannot be made from the data of figure 15 it is illustrative to make an approximate lifetime calculation based on the analysis of reference 7 . The treatment of reference 7 predicted a lifetime based on the time necessary to erode the downstream accelerator web thickness to zero. An endurance test (ref. 7) indicated that the mass sputtering rate of mercury ions at 2400 volts energy was about $4 \mathrm{~g} /(\mathrm{amp})(\mathrm{hr})$.

It will be assumed that the mass sputtering rate of mercury ions on a thruster accelerator grid increases by about a factor of 9 as the ion energy 
increases from 2400 to 40,000 volts. This increase was selected as it is in proportion to the sputtering increase for normally incident mercury ions on molybdenum (fig. 13). The fact that the web thicknesses of the plates utilized in this program were about a factor of three larger than those of the plates utilized in reference 7 then indicates that the total allowable impingement current at 40,000 volts ion energy is about a factor of three less than that utilized on reference 7 at low voltage.

Equation (6) of reference 7 gives a rough estimate of the maximum ideal lifetime of thruster accelerator grids.

$$
\tau=\frac{1.35 \times 10^{6}}{\ell_{\Phi} j_{B}^{2}}\left(\frac{\eta_{U}}{1-\eta_{U}}\right) \text { hours }
$$

This equation contains a numerical constant which was determined on the basis of an accelerator grid lifetime test and a calculation of the chargeexchange impingement current utilizing an equation similar to equation (3). In arriving at this relation in reference 7 it was assumed that the erosion rate was radially uniform and that no charge-exchange ions were formed downstream of the accelerator grid. This equation will be utilized with the following modifications:

(1) The proportionality constant in the lifetime equation will be reduced by a factor of two. It was found experimentally in reference 7 that nonuniform radial grid erosion would reduce the lifetime by about this factor. 
(2) The proportionality constant will further be divided by a factor of three to account for the increased mass sputtering rate at high voltage.

The equation for the lifetime is then:

$$
\tau \approx 2.0 \times 10^{5}\left[\frac{\eta_{\mathrm{U}}}{\ell_{\notin} \mathrm{j}_{\mathrm{B}}^{2}\left(1-\eta_{\mathrm{U}}\right)}\right] \quad \text { hours }
$$

where $j_{B}$ is based on the total thruster area, $A_{O}$.

Equation (5) can be reduced to a function of the propellant utilization efficiency as follows:

(1) The percentage of Child's law ion current will be assumed constant at 30 percent. Figure 15 indicates that this might be an upper limit for long lifetime. The current density in equation (5) of a 50-percent open grid system $\left(A_{I}=0.5 A_{O}\right)$ is then, from equation (2):

$$
\mathrm{j}_{\mathrm{B}} \approx 0.6 \times 10^{-9} \frac{\Delta \mathrm{V}^{3 / 2}}{\ell_{\Phi}^{2}}
$$

(2) The electric field strength, based on the center-to-center grid spacing will be assumed to be constant at $1.5 \times 10^{6}$ volts per meter. Equation (4) then becomes:

$$
\tau \approx 1.5 \times 10^{3} \frac{\eta_{U}}{\left(1-\eta_{U}\right)} \quad \text { hours }
$$

This expression for the accelerator grid lifetime is based on the assumptions of constancy of percentage of Child's law ion current, electric field strength, and charge-exchange cross section. Although the calculation is 
approximate it does indicate that accelerator grid lifetimes of about one and two years can be obtained at propellant utilization efficiencies of 80 and 90 percent, respectively.

A major uncertainty in this calculation of charge-exchange erosion is the value of the mass sputtering rate selected. Other major sputtering factors, such as the presence of direct ion impingement at large angles, could further reduce the lifetime from that given in equation (6). An accurate evaluation of the lifetime of an accelerator grid system therefore still requires extended thruster tests at the specific conditions contemplated for space use.

\section{Power Efficiency}

One of the primary advantages of high-voltage operation is the increase to be expected in the power efficiency, or ratio of beam power to total expended power. As was previously shown (fig. 9), the value of the energy loss per beam ion does not vary substantially over a large range of spacings so that the power efficiency can be expected to reflect directly the increasing ion beam energy.

Figure 16 shows the power efficiency as a function of the net accelerating potential for three values of accelerator spacing. Power losses in the cathode, magnet, accelerator, and ion chamber were included in this data. The power efficiency is a steadily increasing function of net accelerating potential for a fixed value of propellant utilization efficiency. Unfortunately power supply limitations did not allow data to be taken in excess of approximately 70 milli- 
amperes of ion beam current with net accelerating voltages in excess of 50 kilovolts. It was found that the combination of large neutral propellant flow rates and ion beam power would result in vacuum system pressure increases which would lead to anode to ground breakdown. The upper limits were neutral flow rates of about 0.2 equivalent ampere and beam power levels of approximately 7000 watts at net accelerating potentials in excess of 20 kilovolts.

The data of figure 16 indicate that the value of the power efficiency was greater than 0.80 at net accelerating potentials larger than 20 kilovolts. Reduction of the eV/ion would not appreciably affect these data. Because of the small ion beam currents (imposed by Child's law considerations) these losses were always less than 150 watts. The use of permanent magnets and hollow cathodes (ref. 15) would reduce the power losses by about 300 watts or more. The cathode power of the tantalum cathodes was typically about 12 percent of the total thruster power. That of a hollow cathode is about 2 percent. The increase in power efficiency that would result from a 300 watt saving is shown by the projected power efficiency on figure 16 . Also shown on figure 16 are data taken at low voltage with a 20centimeter-diameter thruster (ref. 7). Magnet and cathode losses of 150 and 200 watts, respectively, were used to determine these power efficiencies. The data selected from reference 7 were those closest to 0.80 propellant utilization efficiency and which were available over some range of 
net accelerating potential. The power efficiency, at a fixed net accelerating potential, is not strongly affected by variation of the propellant utilization efficiency between about 0.60 and 0.80. A comparison between the low and high voltage power efficiencies can, therefore, be made.

The extrapolated power efficiencies at high voltage best match the data of reference 7 when the value of the neutral flow rates were approximately equal. In general, the value of the power efficiency increased with the neutral flow rate at a fixed propellant utilization and net accelerating potential. This occurred because of fixed losses that did not vary significantly with ion beam current. The high and low voltage data, with the assumed savings of 300 watts, show that thruster power efficiencies in excess of 0.85 and 0.90 should be obtained at net accelerating potentials greater than about 10 and 20 kilovolts, respectively.

\section{Overall Thruster Efficiency}

The overall thruster efficiency as a function of the net acelerating potential is shown in figure 17(a). For reference the same data is plotted as a function of specific impulse in figure 17(b). The projected power efficiencies from figure 16 were utilized in calculation of overall efficiency. It is seen that the overall efficiency should be greater than 0.80 for net accelerating potentials greater than 16 kilovolts at propellant utilization efficiencies of 0.90 or larger. To achieve this overall efficiency at lower propellant utilizations would require higher net accelerating potentials. 
Data are not presented at values of propellant utilization efficiency greater than 0.91 since this was the largest value at which the thruster operated stably. From previous consideration it would appear that the maximum stable propellant utilization efficiency could probably be increased by decreasing the grid hole size. Because of the spacings required for high voltage (fig. 4), however, and the fact that there exists a maximum ratio of center-to-center spacing to hole diameter (ref. 6 and fig. 12) for good ion focusing the hole diameters could not be significantly reduced.

\section{CONCLUDING REMARKS}

It was found that the maximum supportable electric field strength between accelerator grids of operating thrusters was about $2 \times 10^{6}$ volts per meter over a large range of spacings. This field strength refers to gridto-grid breakdowns after 2 to 20 hours conditioning.

The qualitative variations in $\mathrm{eV} /$ ion were found to be quite similar to that at low voltage. In addition, the $\mathrm{eV} /$ ion was nearly independent of the net accelerating potential and center-to-center grid spacing if the propellant utilization efficiency and percent of Child's law current were held constant.

It was found that the ratio of center-to-center grid spacing to grid thickness should be between 2.5 and 4 to provide good ion focusing. The value of the grid thickness alone did not strongly affect the ion focusing, however, unless the beam current was in excess of approximately 50 percent of Child's law value. 
Estimated lifetimes of accelerator electrodes were in excess of one year at net accelerating potentials between 20 and 70 kilovolts, if the value of the percentage of Child's law is less than about 30 percent and the geometric accelerator parameters are such as to avoid direct ion impingement.

The thruster power efficiency can be expected to be in excess of 0.85 at all net accelerating potentials greater than 20,000 volts. The overall thruster efficiency (the product of the power and utilization efficiencies) was limited to 0.86 in the present study because of discharge chamber stability problems and was substantially less for most conditions investigated. High current densities at high voltage probably require more complex accelerator grid systems to avoid stability problems and excessive ion chamber losses.

\section{REFERENCES}

1. H. R. Kaufman, NASA TN D-585 (1961).

2. E. Stuhlinger, "Ion Propulsion for Space Flight," McGraw-Hill, New York (1964), pp. 150-151.

3. D. Alpert, D. A. Lee, and H. E. Tomasche, Proceedings of the International Symposium on Insulation of High Voltages in Vacuum, MIT Press, Cambridge (1964), pp. 1-12.

4. H. R. Kaufman, NASA TN D-261 (1960).

5. P. D. Reader, NASA TN D-1163 (1962).

6. W. R. Kerslake, NASA TN D-1168 (1962). 
7. W. R. Kerslake, NASA TN D-1657 (1963).

8. S. Nakanishi, NASA TN D-3535 (1966).

9. T. A. Keller, "Transactions of the Seventh National Symposium on Vacuum Technology, " Pergamon Press, London (1960), pp. 161-167.

10. C. Germain and F. Rohrback, in "CR VI Conf. Internat. Phénomènes d'Ionisation dans les Gaz," S.E.R.M. A. , Paris (1963), Vol. 2, p. 111.

11. W. R. Kerslake and E. V. Pawlik, NASA TN D-1411 (1963).

12. M. J. Kofoid, AIEE Trans., Part III, $\underline{79}, 991$ (1960).

13. M. J. Kofoid, AIEE Trans., Part III, 79, 999 (1960).

14. R. T. Bechtel, G. A. Csiky, and D. C. Byers, AIAA Paper 68-88 (1968).

15. P. D. Reader, NASA TN D-2587 (1965).

16. D. C. Byers, W. R. Kerslake, and J. S. Grobman, NASA TN D-2401 (1964).

17. H. R. Kaufman, NASA TN D-3041 (1965).

18. E. V. Pawlik, P. M. Margosian, and J. F. Staggs, NASA TN D-2804 (1965).

19. A. von Engel, "Ionized Gases," Clarendon Press, Oxford (1955), p. 112.

20. R. M. Kushnir, B. M. Palyukh, and L. A. Sena, Bull. Acad. Sci. USSR, $\underline{23}, 995(1959)$.

21. I. Popescu Iovitsu and N. Ionescu-Pallas, Soviet Phys. -Tech. Phys., $\underline{4}$, $781(1960)$.

22. G. K. Wehner, J. Appl. Phys., 30, 1762 (1959). 
23. W. R. Mickelsen and H. R. Kaufman, Brit. Interplanetary Soc. J., 19,369 (1964). 
$\stackrel{n}{n}$

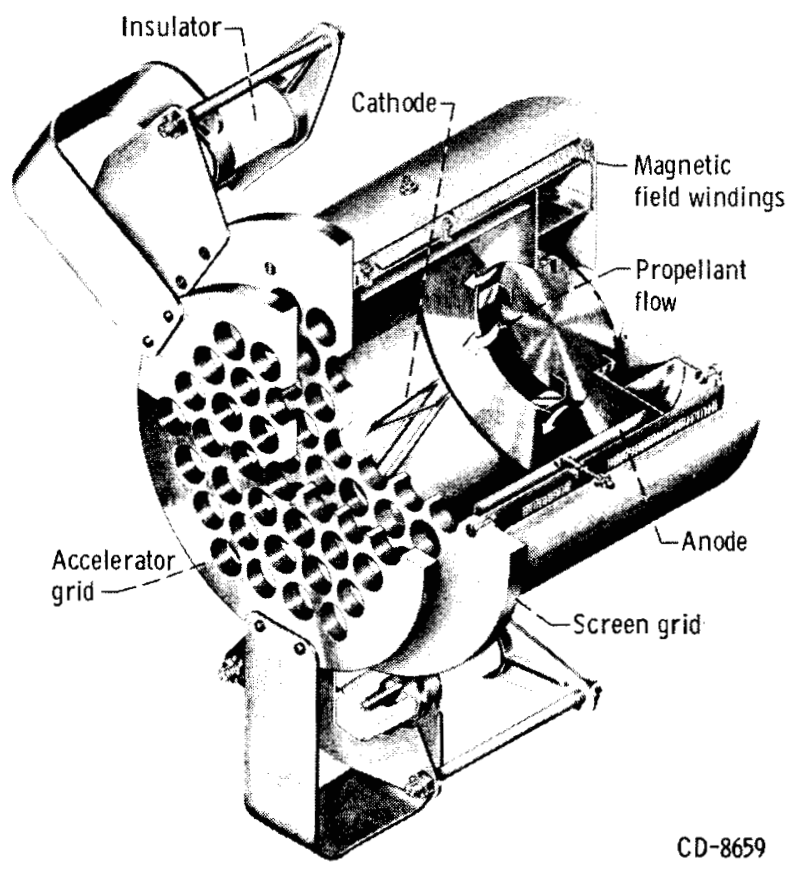

Figure 1. - 20-Centimeter Kaufman thruster.

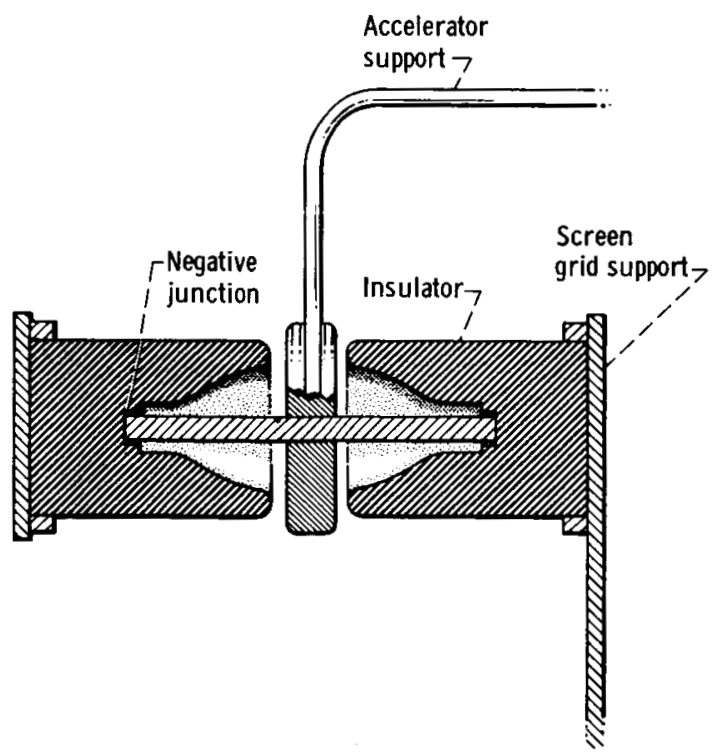

Figure 2. - Sketch of the insulator and mounts. 
$m$
$m$
1
1

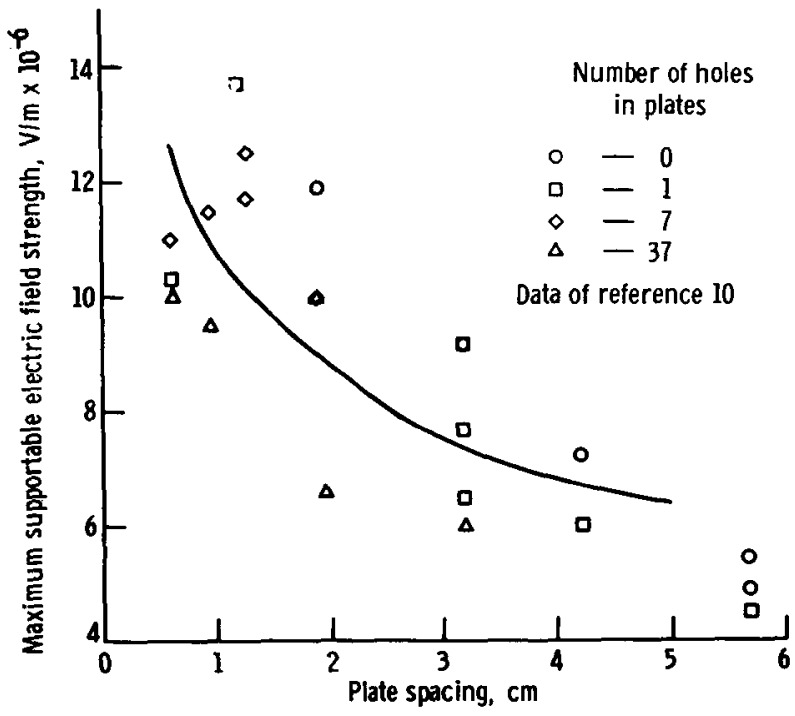

Figure 3. - Effect of spacing on the maximum supportable electric field strength between stainless steel plates. Plate diameter, $25 \mathrm{~cm}$; hole size, $22 \mathrm{~cm}$.

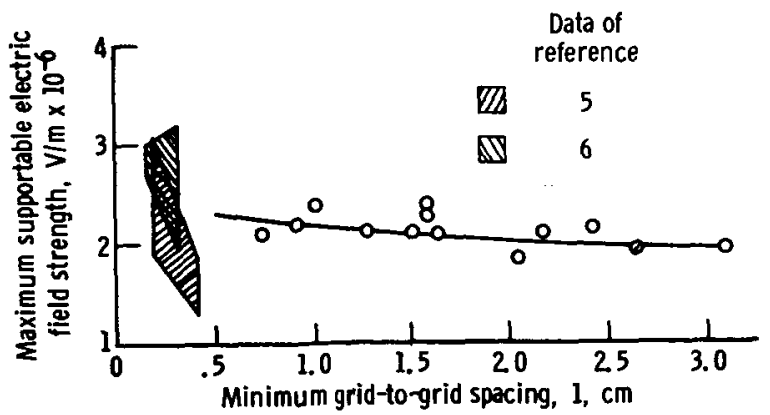

Figure 4. - Maximum supportable electric field strength between the accelerator grids of an operating electronbombardment thruster as a function of the grid spacing. t, $1.18 \mathrm{~cm} ; \mathrm{D}, 2.2 \mathrm{~cm}$; 37-hole grid. 
年

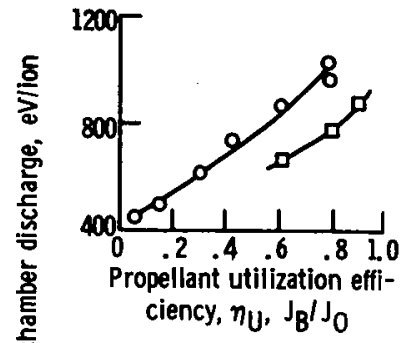

(a)

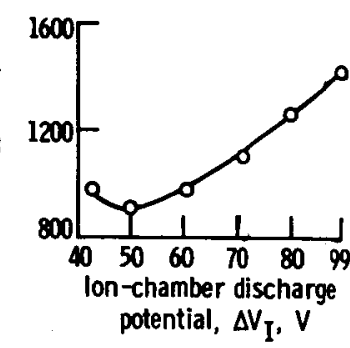

(c)

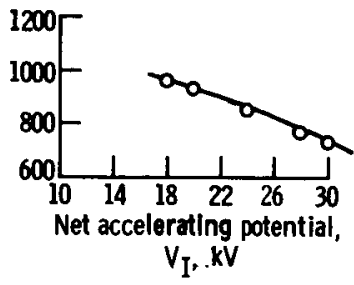

(b)

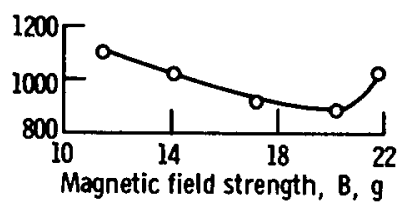

(d)

Figure 5. - lon-chamber performance as a function of several thruster parameters. $\Delta V_{I}, 50 V_{;} V_{I}, 20 \mathrm{kV} ; J_{0}, 0.165 A_{\text {; }}$ $\eta_{U}, 0.79 ; B, 17.4 \mathrm{~g} ; R, 0.8 ; Z_{\phi} / 0,1.29 ; 0,2.2 \mathrm{~cm} ; t$, $1.18 \mathrm{~cm}$; 37-hole grid; unless otherwise noted.

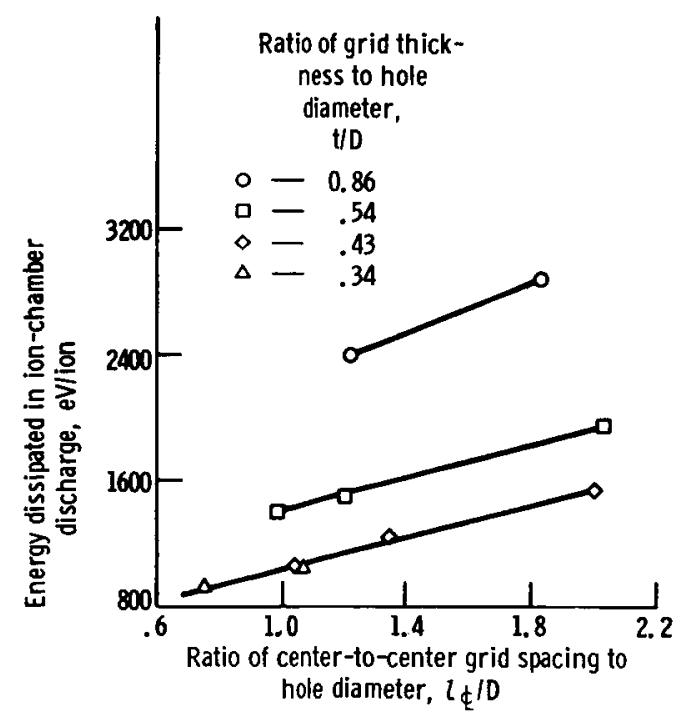

Figure 6. - Effect of center-to-center grid spacing on ion-chamber performance. $\Delta V_{I}$, $50 \mathrm{~V} ; \mathrm{V}_{\mathrm{I}}, 16 \mathrm{kV} ; \mathrm{J}_{0}, 0.165 \mathrm{~A} ; \eta_{\mathrm{U}}, 0.12 ; \mathrm{B}$, $17.4 \mathrm{~g} ; \mathrm{k}, 0.8 ; \mathrm{D}, 2.2 \mathrm{~cm}$; 7-hole grid. 


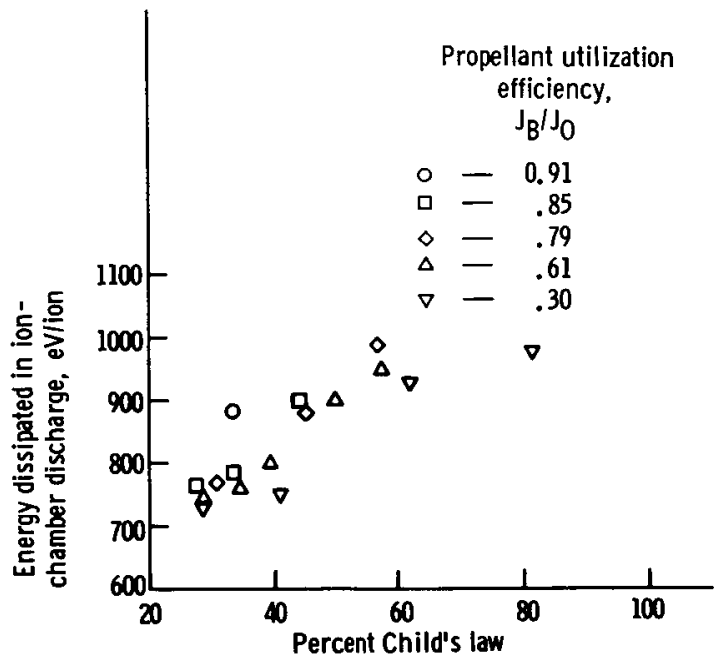

Figure 7. - Effect of percent Child's law on ionchamber performance. $\Delta V_{I}, 50 V_{i} J_{0}, 0.165 A_{i}$ B, $17.4 \mathrm{~g} ; \mathrm{R}, 0.8 ; L_{\mathrm{q}} / \mathrm{D}, 1.29 ; \mathrm{D}, 2.2 \mathrm{~cm} ;$ UD. 0.54 , 37-hole grid.

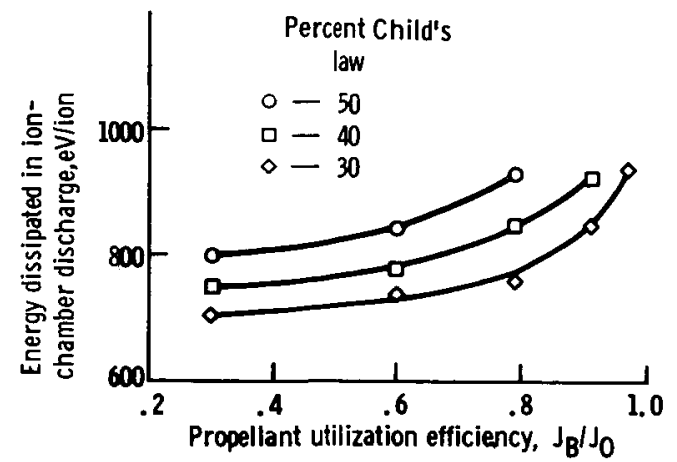

Figure 8. - Effect of propellant utilization efficiency on ion-chamber performance. $\Delta V_{I}$, $50 \mathrm{~V} ; J_{0}, 0.165 \mathrm{~A} ; \mathrm{B}, 17.4 \mathrm{~g} ; l_{4} / 0,1.29$;

$D, 2.2 \mathrm{~cm} ; \quad U D, 0.535 ; \cdot 37$ thole grid. 


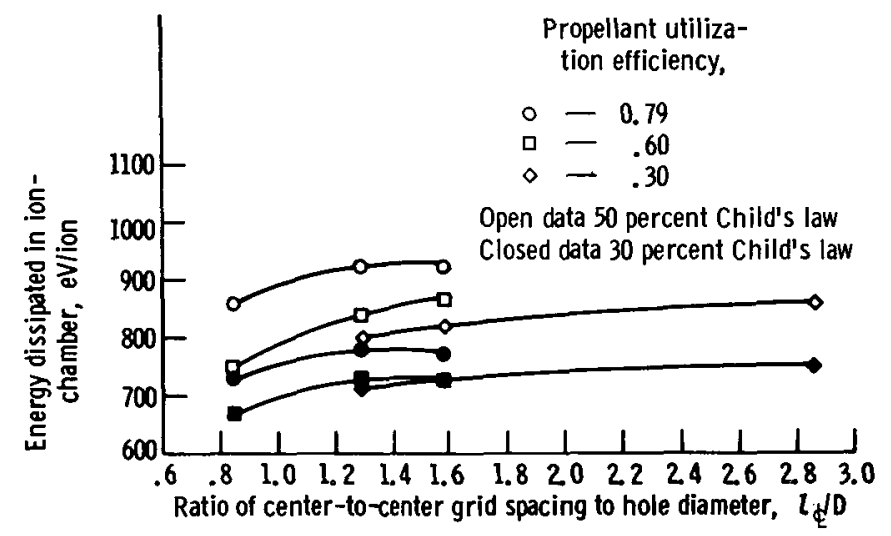

Figure 9. - Effect of center-to-center grid spacing on ionchamber performance at several values of percent Child's law and propellant utilization efficiency. $\Delta V_{I}, 50 V_{;} J_{0}, 0.165$; $B, 17.4 \mathrm{~g} ; \mathrm{R}, 0.8 ; 0,2.2 \mathrm{~cm}$ t $10,0.54$;7-hole grid.

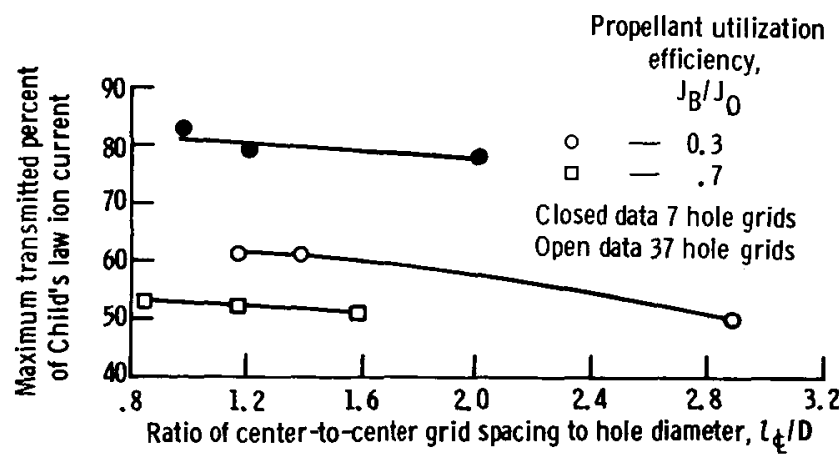

Figure 10. - Effect of spacing on the maximum percent Child's law ion current transmitted. $\Delta V_{I}, 50 V_{;} J_{0}, 0.165 \mathrm{~A} ; B$, $17.4 \mathrm{~g} ; \mathrm{R}, 0.8 ; \mathrm{D}, 2.2 \mathrm{~cm} ; \mathrm{t} / \mathrm{D}, 0.54$. 
- $\frac{m}{m}$
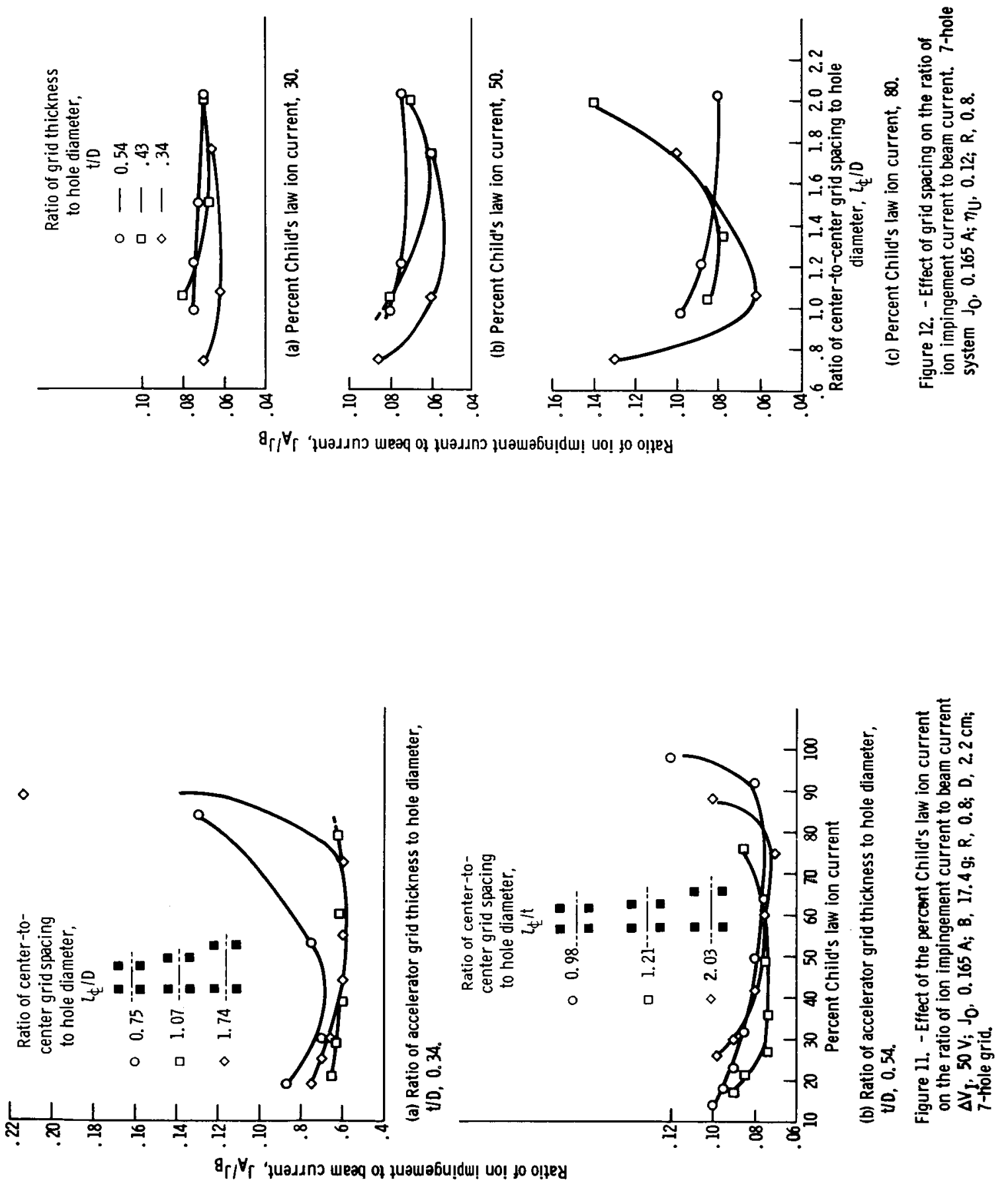

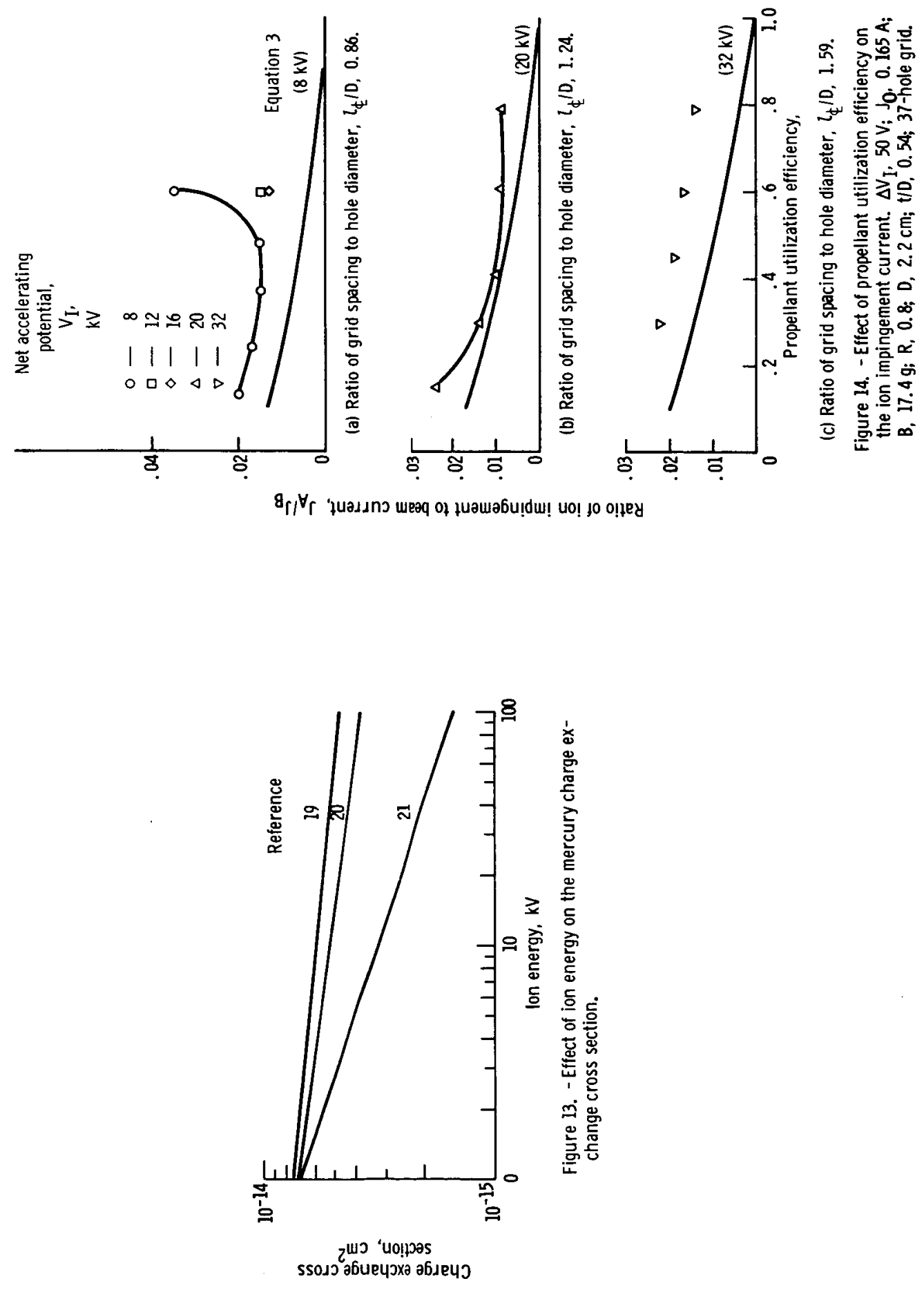
$M$
$\stackrel{n}{N}$
$M$
1
1
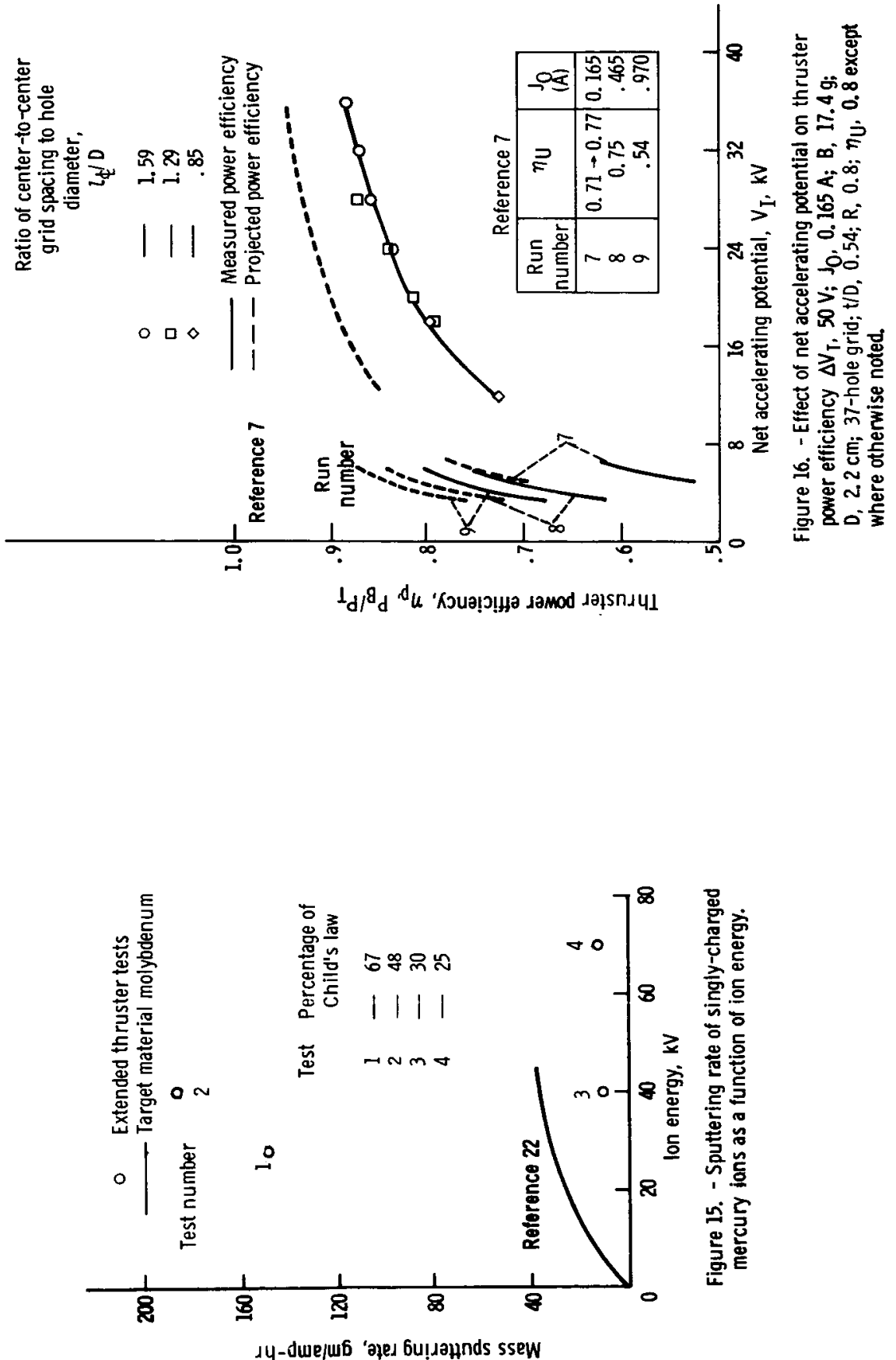


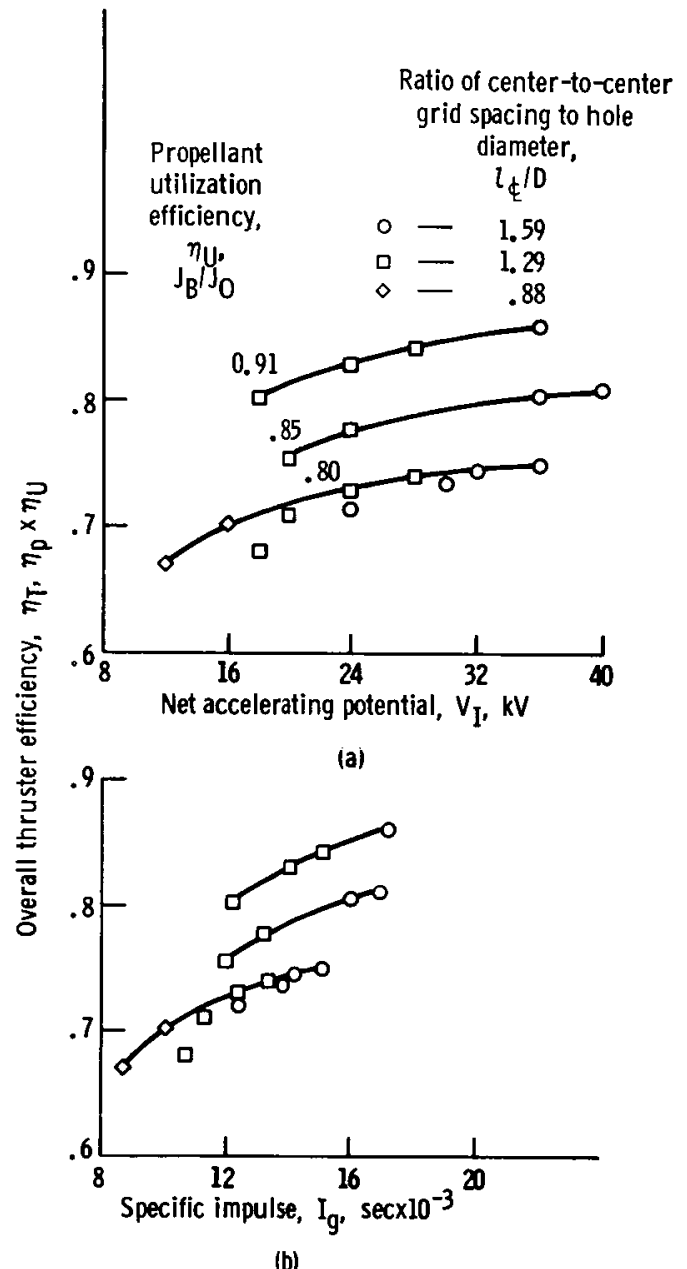

Figure 17. - Overall thruster efficiency as a function of net accelerating potential and specific impulse. $\Delta \mathrm{V}_{\mathrm{I}}, 50 \mathrm{~V} ; \mathrm{J}_{0}, 0.165 \mathrm{~A}_{\mathrm{i}}$ $B, 17.4 \mathrm{~J} ; D, 2.2 \mathrm{~cm} ; \mathrm{VD}, 0.54$, R, 0.8. 